\title{
Experience of using high-rigidity bearing reinforcement in monolithic lightweight concrete slabs
}

\author{
Artem Davidyuk ${ }^{1 *}$, Tejmuraz Guladze ${ }^{2}$, Yuliya Kustikova $^{1}$ and Timofey Laryushkin ${ }^{3}$ \\ ${ }^{1}$ Moscow State University of Civil Engineering, Yaroslavskoe shosse, 26, Moscow, 129337, Russia \\ ${ }^{2}$ Joint-Stock Company 'Design \& Engineering Bureau of Concrete and Reinforced Concrete', 2-nd \\ Institutskaya street., 6, p. 15 A, Moscow, 109428, Russia \\ ${ }^{3}$ Kucherenko research institute of building constructions 109428, Moscow, 6 2nd Institutskaya Str., \\ Russia
}

\begin{abstract}
The article describes the experience of erecting lightweight concrete monolithic slabs with the use of reinforcing bars of increased rigidity. As a result, a reduction in costs of $25 \ldots 30 \%$, compared with the floors of heavy concrete without pre-stressed reinforcement is reached.
\end{abstract}

\section{Introduction}

In large cities where there is an acute shortage of land, it is necessary to erect high-rise buildings (up to 100 floors and higher). At that, because bases under them are in most cases weakened by various engineering lines, to reduce the building mass, high-performance lightweight concretes came to be used in frames. The main advantage of lightweight concretes is their low mean density compared to the mean density of heavy concretes. Usage of lightweight concretes in all structures of the frame allows reducing the mass of buildings, lower design loads on structures, and simultaneously reduce consumption of bars.

However, at present, in Russia, lightweight concretes are used in bearing structures of the frame much rarer than conventional heavy concretes of compression strength B15 and higher. The main reason is low strength of coarse aggregate, high consumption of cement for fabrication of high-performance concretes where weak aggregates are used; worse physical and mechanical properties compared to a heavy concrete (low elasticity modulus, increased shrinkage and creep values, poorer corrosion resistance, limited possibility of use in aggressive media, and so on. Besides, to prevent concrete mix foliation, formation of structures is carried out using weights, which creates certain difficulties during fabrication of structures of these concretes).

\section{Materials and methods}

To improve the technological and strength parameters of the above concretes, the Research Institute of Concrete and Reinforced Concrete [1] has developed lightweight concretes from

\footnotetext{
* Corresponding author: davidyukart@ mail.ru
} 
expanded clay aggregates with addition of modifiers. As proven by studies [1], such concrete mixes do not foliate during formation of a structure while concrete itself is characterized by improved strength compared to the same concretes without additives.

To increase rigidity and crack resistance of girders and beams made with lightweight concrete in floors having spans of $5 \mathrm{~m}$ and more, pre-stressed bars are used [2].

In contemporary construction, one of promising directions is use of frames with bars stressing in the course of erection of monolithic reinforced concrete floors, which allows implementing reinforced concrete floors with medium-size and large spans at minimum material cost.

STEFS JSC, jointly with Design - Technological Bureau of Concrete and Reinforced Concrete JSC, design a monolithic lightweight reinforced concrete floor with bearing reinforcement of increased rigidity for the basement level of Metropol Hotel in Moscow. The layout plan and diagrams of monolithic floor reinforcement are given on figure 1.

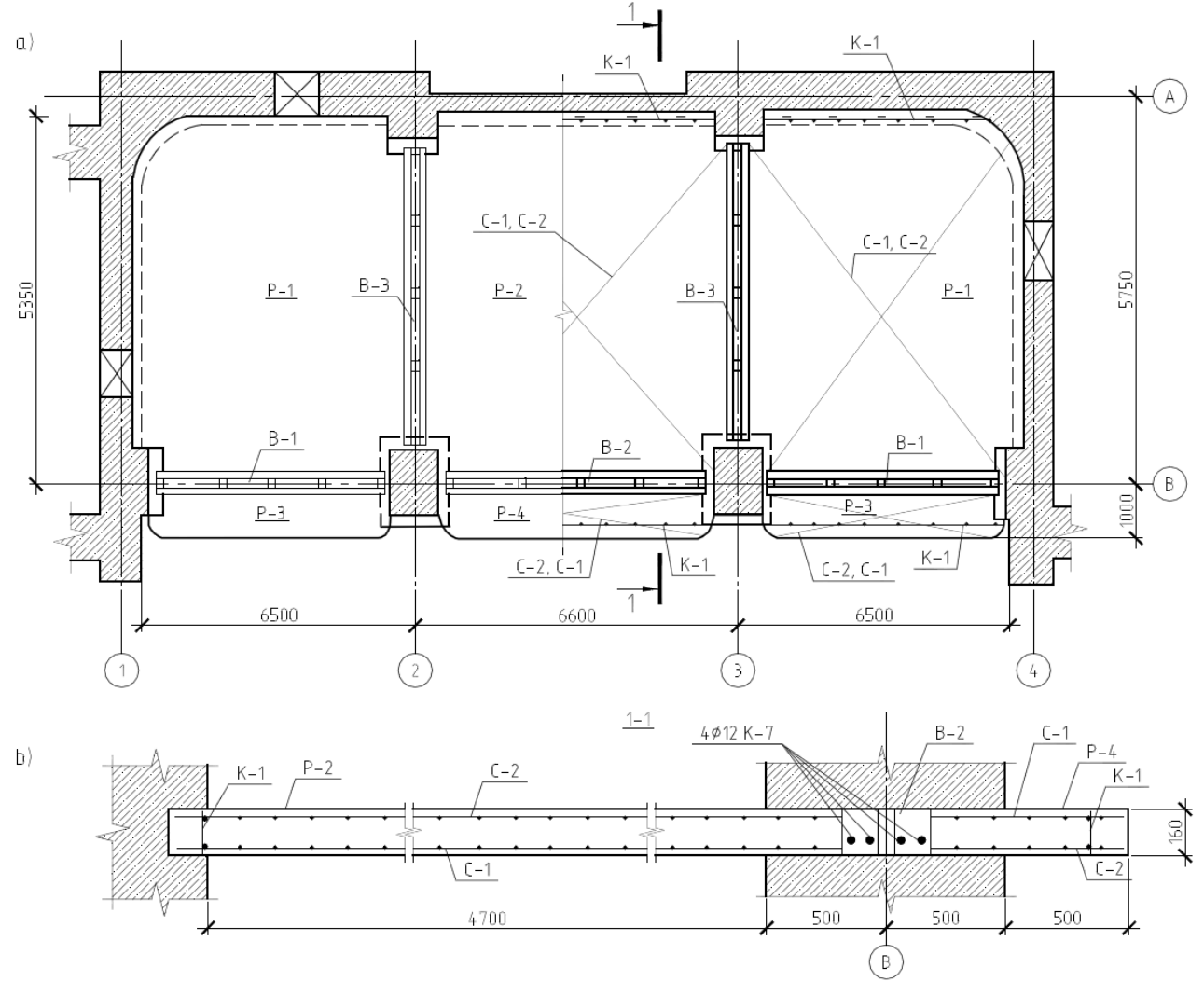

Fig. 1. Monolithic floor: a) floor reinforcement plan and diagram; b) section 1-1

The monolithic floor consists of slabs (P-1 and P-2) having plan dimensions 5.35x6.6 m and back slabs (P-3 and P-4) having plan dimensions 1.0x6.6 m. Slabs P-1 and P-2 rest freely on the bearing walls along the contour and on pre-stressed metal beams (B-1), (B-2), and (B3 ), while back slabs rest only on beams (Б-1) and (Б-2) (see figure 1.). The floor thickness did not exceed $16 \mathrm{~cm}$.

As prestressed reinforcement, wire-rope reinforcement of class $\mathrm{K}-7$ having diameter $\mathrm{d}=12$ $\mathrm{mm}$ (GOST 13840-68); as nonprestressed reinforcement, A400C in the form of bar-mats C1 and flat frames $\mathrm{K}-1$, also $\mathrm{Bp}-1$ in the form of bar-mats $\mathrm{C}-2$ crosswise reinforcement flat frames $\mathrm{K}-1$ were used. 
To increase rigidity of structures, metal beams (B-1, B-2 and B-3) were preliminary stressed with wire-rope reinforcement (see figure 2a). Preliminary compression forces (Ps) were applied with eccentricity $\mathrm{e}=40 \mathrm{~mm}$ to provide the required structural hogging according to SP63.1330.2012. In this instance, stress in bars did not exceed $\sigma s=1110 \mathrm{MPa}$.

Subjected to stress reinforcement was fixed with the help of anchors (sleeves from steel 3 , length $\mathrm{l}=80 \mathrm{~mm}$ ) and specially welded plates on metal beams (see figure 2, section 1-1).
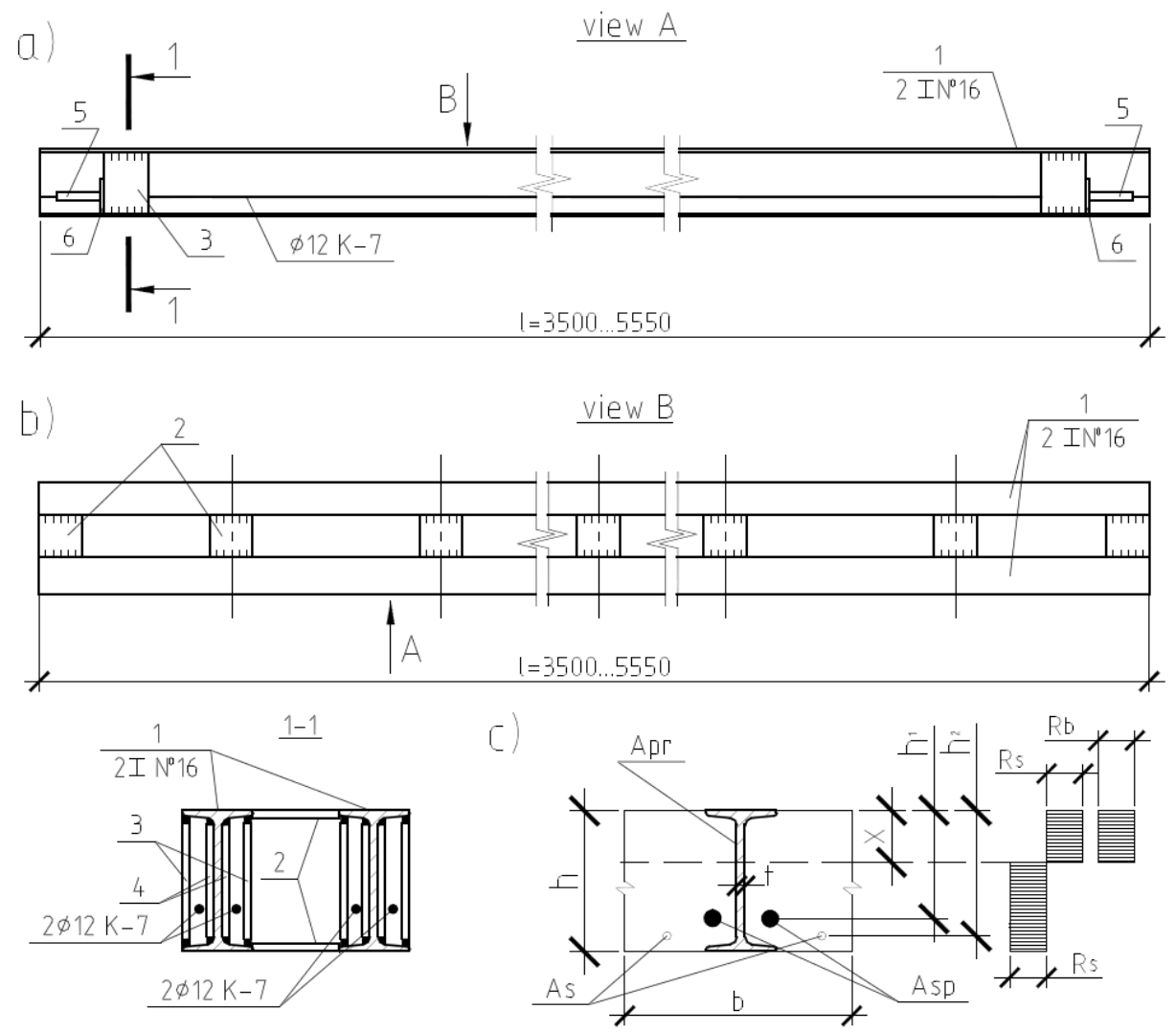

Fig. 2. Metal beams (B-1, B-2, B-3): a) view A; b) view B; c) structural design of floor cross-section in strength calculation. 1 - metal W-shape No.16; 2,3,4 - metal plates; 5 - anchor (pressed sleeve); 6 fastener (steel plate).

Preliminarily, wire-rope reinforcement was notched at the point of anchor sleeve installation with the help of hydraulic jack GD-20a following method [3], thereafter, wirerope reinforcement was inserted into pressing device (OPU-30) and in points of notches, sleeves were pressed, which, according to studies [4], increases the reinforcement pulling strength of sleeve anchorage approximately 1.5 -fold compared to wire-rope reinforcement without notches.

After all reinforcing elements were laid in the formwork, concreting was performed using expanded clay aggregate concrete having compression strength B27.5 and volume density D1800, with addition of concrete modifier MB10-30 superplasticizing agent C-3 [1].

The same technology was used in the development and erection of monolithic lightweight reinforced concrete floor with reinforcement of increased rigidity for the 2-floor addition to the 4-floor 2-span frameless building with spine walls at the address: Moscow, Kozhevnicheskaya Street, 1, where the building span amounted to $8.6 \mathrm{~m}$ and metal beams 
were spaced at $3-4 \mathrm{~m}$. Floor thickness did not exceed $22 \mathrm{~cm}$. That floor was the base of the 2floor addition to the 4-floor building, which was erected without temporary supports (for formwork) and without moving institution employees.

Design - Technological Bureau of Concrete and Reinforced Concrete JSC also developed the design of reinforcing monolithic floors of a 3 -floor kindergarten in Kurovskoe. Due to shortage of reinforcement, floors with spans of up to $6.3 \mathrm{~m}$ were deflected by more than $60 \mathrm{~mm}$ at slab thickness of $160 \mathrm{~mm}$. Reinforcing was performed on the total area of $3200 \mathrm{~m} 2$; the system of post-stressed external reinforcement based on bars of deformed sections d16 from heat-treated steel of grade A800t was applied. Reinforcement was fixed with the help of friction abutment $[5,6]$ installed on floors in the zone of zero moment of flection and fastened with high-performance pins M24 of strength grade 8.8 .

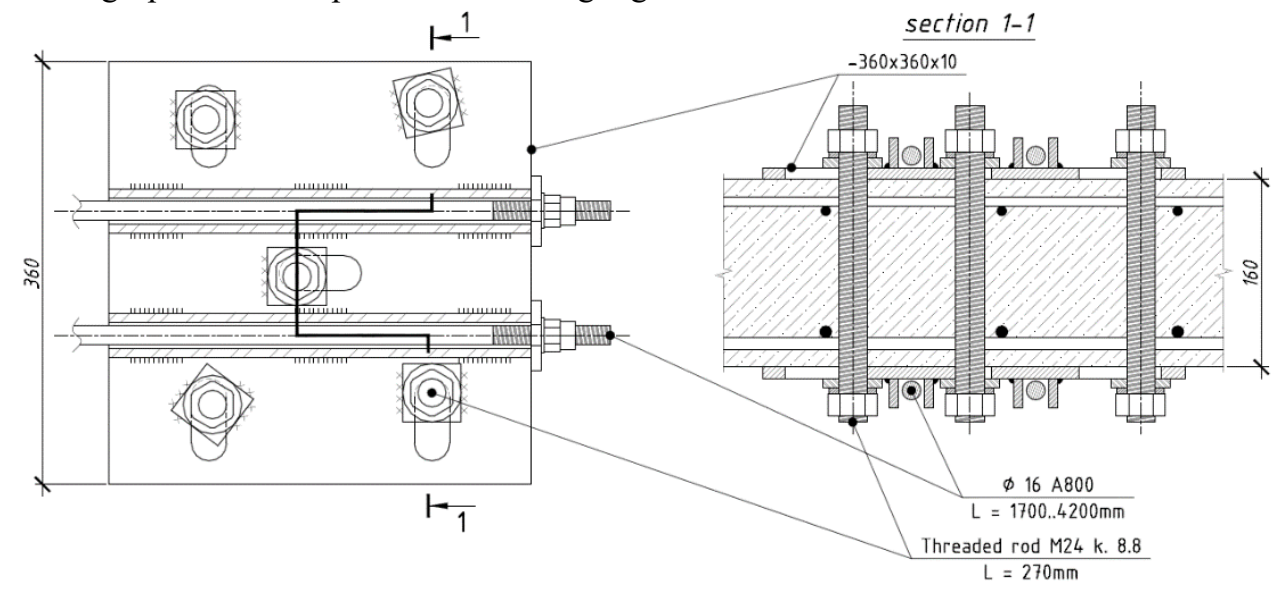

Fig. 3. Overview of section of friction abutment on the floor.

Each end of reinforcement bar was threaded to M14, tension was achieved by tightening nuts of increased length $(40 \mathrm{~mm})$ at bar ends; tension was checked using a torque wrench based on the results obtained during testing.

Reinforcement tension allowed not only to ensure full involvement (stress in bars being $\sigma s=440 \mathrm{MPa}$ ), but also rise floors by $2-5 \mathrm{~mm}$ in spite of inelastic concrete behavior several years after concreting. Such structures are highly cost-efficient for buildings with spans, loads and operating conditions that make use of nonpresstressed reinforced concrete structures technically impossible or leads to excessive overconsumption of concrete and steel to provide the required rigidity and bearing capacity of structures. In addition to the economic effect, construction of buildings and facilities using the technology of prestressing reinforcement elements in erection of buildings from monolithic reinforced concrete allows significantly extending architectural planning opportunities for designed buildings.

\section{Results and discussion}

Use in monolithic construction of prestressed reinforced concrete as a structural material gives almost unlimited opportunities for interior spatial design of buildings. Such parameters as column spacing up to $20 \mathrm{~m}$, flat beamless floors of reduced thickness of up to $27 \mathrm{~cm}$, cantilever elements protruding up to $6 \mathrm{~m}$ along with wide possibilities for layout of walls and partitions determine a qualitative breakthrough in planning and functional characteristics of a building and provide construction cost reduction of up to $30 \%$ 


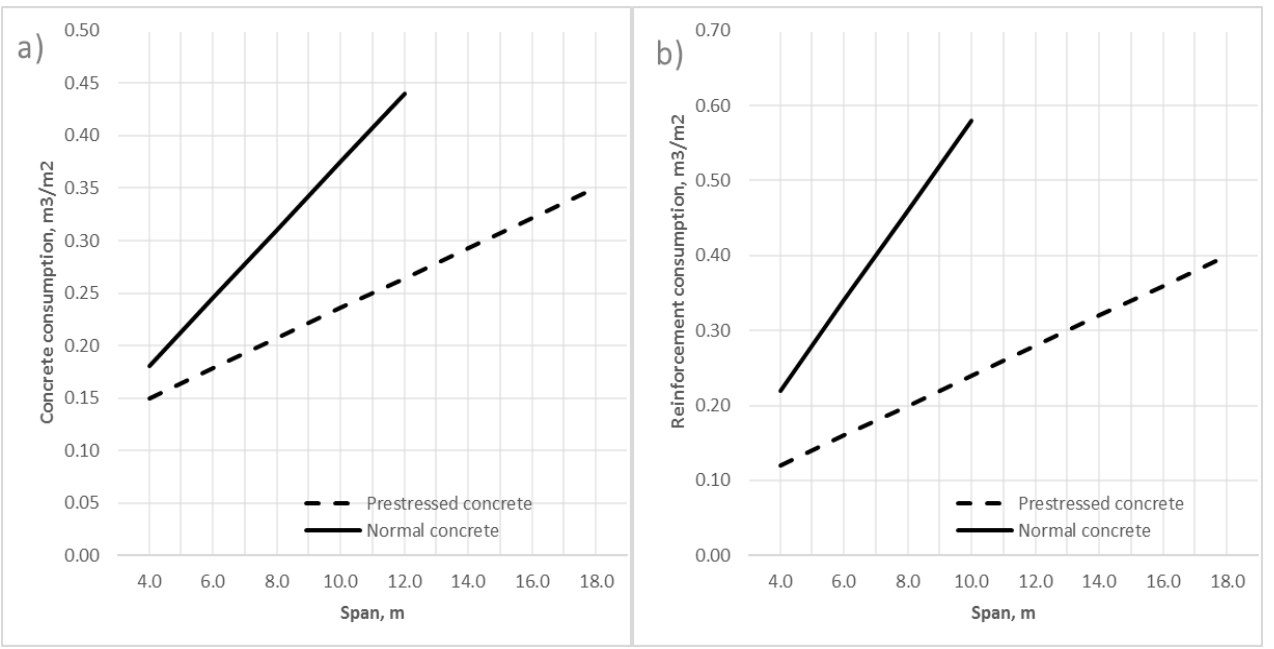

Fig. 4. a) Changes of concrete consumption in structures with increase of spans when conventional and prestressed reinforced concrete are used; b) Changes of reinforcement consumption.

Besides, the possibility of erecting cantilevers with a long unsupported length creates an opportunity for designing and erecting buildings that would have various architectural appearance thanks to wide enough limits for variation of the shape of building contours in the horizontal section.

Application of prestressed reinforced concrete allows to:

- increase considerably spacing between columns without increasing material intensity $[7,8]$;

- $\quad$ erect cantilevers protruding up to $6 \mathrm{~m}$ without additional reinforcement;

- decrease the reduced thickness of floor slabs to $14 \mathrm{~cm}$;

- $\quad$ reduce reinforcement steel consumption by 35 to $75 \%$;

- $\quad$ reduce the commercial concrete consumption by 5 to $30 \%$;

- $\quad$ reduce labor intensity by 5 to $25 \%$;

- $\quad$ reduce energy intensity of production by up to $30 \%$ [9];

- $\quad$ reduce the prime construction cost by 10 to $30 \%$ [10].

Comparative efficiency was calculated based on generalized data of 20 construction projects of different functional purpose.

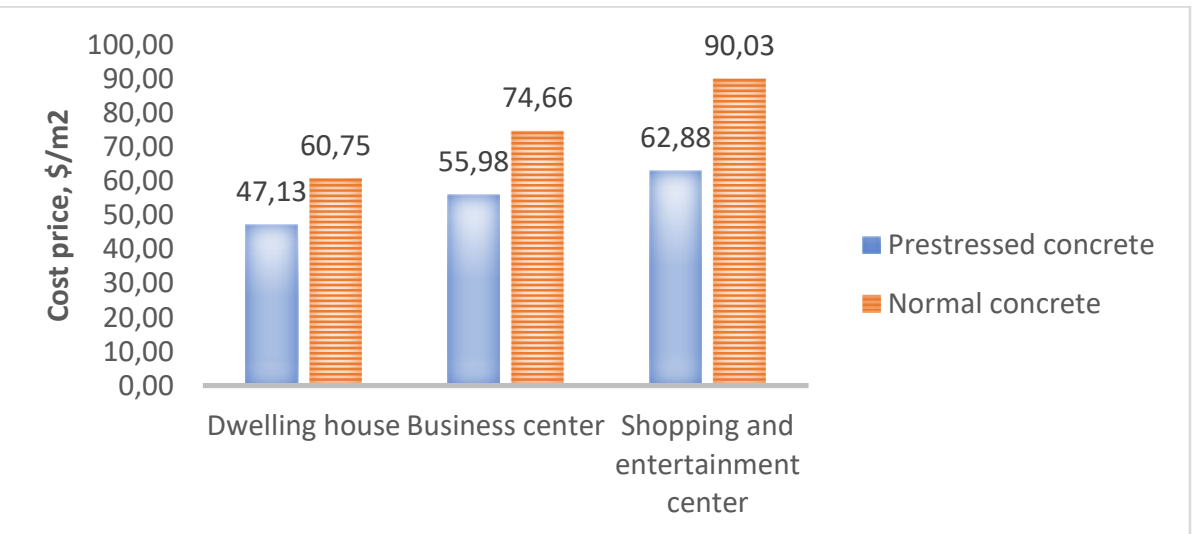

Fig. 5. Reduction of the cost of erecting reinforced concrete structures by use of prestressed reinforced concrete. 


\section{Conclusions}

Implementation of projects using advanced structural and technological designs of erection of buildings implying use of the technology of prestressing reinforced concrete allows overcoming the main drawbacks of monolithic construction: high prime cost, labor intensity and duration of construction and installation operations.

At present, the technology is used in the construction of buildings and facilities of different purpose: residential, offices, production, warehousing, and shopping. The geography of application of prestressed reinforced concrete is also wide. Along with Moscow, cities near Moscow, Saint Petersburg, Veliky Novgorod, Yaroslavl, Voronezh, Saratov are developed similarly. Extension of areas of application of prestressed concrete in construction is important. As practice shows, it can be widely and efficiently use in civil and housing construction.

\section{References}

1. T.I. Guladze, V.N. Yarmakovsky, I.S. Khaimov and V.G. Asatryan, II All-Russia (International) Conf. on Concrete and Reinforced Concrete, 2, 100-104, (2005)

2. V.I. Davgalyuk and G.L. Katz, Structures from lightweight concretes for multi-floor frame buildings, (1984)

3. V.G. Asatryan, The fastening technique and the method of design of wire and wire-rope reinforcement anchor design. Concrete at the cusp of the third millennium, 2, 964-967, (2001).

4. T.I. Guladze, Determination of maximum forces of pulling from anchors (of pressed sleeve types) of stressed wire-rope reinforcement in site prefabrication conditions, 5862, (2011)

5. S.Yu. Kaptelin and G.N. Rostovykh, General engineering problems and methods to address them, 147-154, (2015).

6. A.S. Shirokih, Oil and Gas Engineering, 2, (2005).

7. T.A. Zinnurov, A.A. Piskunov, Russian jour. of transport engineering, 4(2) 2-8, (2017)

8. N.P. Solov'ev and I.N. Solov'ev, Materials of the International (VII All-Russian) Conference NADCR, 107-111 (2012).

9. L.V. Asatryan, Construction materials, equipment, technology of the XXI-th century, 4, 68-71, (2009)

10. V.S. Spirina, Technical Sciences 11, 45-46, (2015). 